Humeniuk, R., Henry-Edwards, S., Ali, R., et al (2010) The Alcohol, Smoking and Substance Involvement Screening Test (ASSIST): Manual for Use in Primary Care. WHO.

Koronfel, A. A. (2002) Suicide in Dubai, United Arab Emirates. Journal of Clinical Forensic Medicine, 9, 5-11.

McLellan, A. T., Luborsky, L., Woody, G. E., et al (1980) An improved evaluation instrument for substance abuse patients. Journal of Nervous Mental diseases, 168, 26-33.

Rawson, R. A., Shoptaw, S. J., Obert, J. L., et al (1995) An intensive outpatient approach for cocaine abuse treatment: the Matrix Model. Journal of Substance Abuse Treatment, 12, 117-127.

Sarhan, H. A. S. (1995) Drug Abuse in the United Arab Emirates. PhD thesis, University of Newcastle upon Tyne.
United Nations Office on Drugs and Crime (2011) World Drug Report 2011. UNODC.

United Nations Office on Drugs and Crime (2013) International Standards on Drug Use Prevention. UNODC.

Wanigaratne, S., Salas, S. \& Strang, J. (2007) Substance misuse. In Textbook of Cultural Psychiatry (eds D. Bhugra \& K. Bhui), pp. 242-254. Cambridge University Press.

World Health Organization (2006) Lexicon of Alcohol and Drug Terms. WHO.

World Health Organization (2014) Global Status Report on Alcohol and Health. WHO.
MENTAL HEALTHLAW PROFILE

\title{
Kenya's mental health law
}

\author{
David M. Ndetei, ${ }^{1}$ Job Muthike ${ }^{2}$ and Erick S. Nandoya ${ }^{3}$
}

${ }^{1}$ University of Nairobi, Kenya; Africa Mental Health Foundation, emaildmndetei@amhf.or.ke

${ }^{2}$ Mental Health, Bucks New University, UK

${ }^{3}$ Africa Mental Health Foundation
Kenya's Mental Health Act 1989 is now outdated. It is a signatory to international rights conventions that provide for state protection of the rights of people with mental illness, their property and their treatment. There is, however, a glaring failure to implement the existing legal provisions. A new Mental Health Bill that aims to respond comprehensively to the challenges affecting mental health services in Kenya is awaiting enactment.

\section{Colonial legacy}

The English Mental Health Act 1959 was in use in Kenya when the country gained independence in 1963. That Act recognised the need for medical treatment of mental illness and emphasised the provision of community services. It introduced the medical model in mental health treatment in Kenya (Jenkins et al, 2011).

\section{Kenyan mental health law}

While the 1959 legislation might have been progressive for its time, it offered little protection of patients' basic human rights. In Kenya, it was replaced with the Mental Health Act of 1989, which attempted to further decentralise services. It allowed any hospital to be gazetted as a mental health hospital (Petersen et al, 2011). Admission procedures were simplified under the Act and there was an attempt to integrate mental health services within the nation's general health services (Monteiro et al, 2014). It allowed for the provision of voluntary treatment of people with mental illness and created a regulatory board to oversee its implementation. This Act remains in force (Marais \& Peterson, 2015).

The 1989 Act has not been amended since 1991 . As a result, some of its provisions are noticeably out of date and even at odds with Kenya's constitution and incompatible with present international standards. The main shortcoming is its overemphasis on in-patient treatment. Although it offers some protection for in-patients regarding ill treatment in hospital, administration of their estates and the examination of females, it fails to address the patient's right to information, consent to treatment, confidentiality and conditions in mental health facilities (Muga \& Jenkins, 2010). It also fails to embrace the World Health Organization's model of mental health treatment which recommends an optimum mix of mental health services such as counselling, psychotherapy, aftercare and rehabilitation services besides pharmacological interventions (Muga \& Jenkins, 2010). Further, it does little to promote community mental health services at the primary care level and makes no distinction between mental illness and mental disability.

\section{Mental health law implementation and review}

There has been a notable failure to implement some of the Act's provisions. Section 4, which provides for the establishment of a national Mental Health Board, and section 7, which provides for the appointment of district mental health councils, have not been adequately implemented. Lack of budgetary allocation has been cited as the main reason (Jenkins et al, 2011).

The Kenya Mental Health Bill 2014 has been drafted and is in parliament awaiting enactment into law. It is hoped that when the Bill is eventually enacted, it will address the shortcomings of the 1989 Act and bring Kenya's mental health services to a par with international standards. The primary aim of the Bill is to reduce inequalities in the allocation of health resources and to improve access to services. This will be through provision of a framework to ensure there is a national mental health plan to review mental health services and develop rules and regulations that will ensure the implementation of the Act. The policy will further develop guidelines and standards on prevention, 
care, treatment and rehabilitation, and develop a national mental health management system (Kiima \& Jenkins, 2010).

The Bill has set out guidelines to ensure that mental health services are affordable and accessible to all people. It will give both central government and local government in Kenya mandates to determine and coordinate the implementation of policies in a manner that will ensure the provision of mental healthcare at health facilities at the community, primary, secondary and tertiary levels. It will ensure decentralisation of services in order to reach every county and persons distant from the major towns like Nairobi and Mombasa. The Bill guides national and local government in promoting community mental health by providing appropriate resources, facilities, services, personnel and programmes. This will allow persons with mental illness to attend services at the community level; it will also allow for the development of outpatient services for persons with mental illness and clinics in health centres and general hospitals all over the country. Indeed, one county (Makueni County) is already implementing such measures with technical support from Africa Mental Health Foundation (AMHF) with seed funding from Grand Challenges Canada (GCC).

The Bill has also set forth guidelines for establishing a mental health regulating body, to be known as the Mental Health Board, which will be charged with responsibility for regulating mental health services, including advising the government, establishing and inspecting mental health facilities, and investigating any matters related to mental health services or programmes (Petersen $e t$ al, 2011).

\section{Kenya's commitment to international conventions}

Kenya is signatory to international rights conventions that provide for state protection of the rights of people with mental illness, their property and their treatment (Omar et al, 2010). Of significance is article 12 of the Convention on the Rights of Persons with Disabilities, to which Kenya has been a signatory since 2008. This Convention addresses the legal capacity of persons with disabilities, their recognition before the law and decision making (Kiima \& Jenkins, 2010). It obliges member states to provide people with disabilities with access to any support that they may require in exercising their legal capacity, as well as safeguards to ensure that such support is not abused. Using a simplistic definition of mental illness as a disability of the mind, the Convention provides protection of the rights of mentally ill people and forms the basis for claims to relevant services from the state (Bartlett $e t$ $a l, 2011)$. The Convention's legal status is protected in subsection 5 of article 2 of the Constitution of Kenya (2010). In its own right, the Constitution provides for fundamental rights and freedoms to all persons, including those with mental illness.

The country has also adopted the World Health Organization's Global Mental Health
Action Plan 2013-2020. Its objectives are to ensure effective leadership and governance of mental health services, to provide mental and social care services in community-based settings, to implement strategies for the promotion of mental health and the prevention of mental ill-health, and to strengthen information systems and research in mental health (Kigozi et al, 2010). This is an effort to bring the state sector, the private sector and civil society together in developing policies aimed at improving mental health services, preventing mental illness and promoting recovery (Marais \& Peterson, 2015).

\section{Conclusion}

The new Mental Health Bill aims to bring mental health services and the welfare of mentally ill people in Kenya on to a par with international standards. There is concern, however, about a glaring failure to implement existing legal provisions, which is coupled with lack of awareness of the same on the part of both the public and some mental health professionals (Jenkins et al, 2011). This lack of awareness may also explain the lack of civil society action and effort aimed at prompting the state to fully implement the available legal provisions and policies (Raja et al, 2010).

\section{References}

Bartlett, P., Jenkins, R. \& Kiima, D. (2011) Mental health law in the community: thinking about Africa. International Journal of Mental Health Systems, 5, 1-7. DOI https://doi.org/10.1186/1752-44585-21.

Jenkins, R., Mussa, M., Haji, S. A., et al (2011) Developing and implementing mental health policy in Zanzibar, a low income country off the coast of East Africa. International Journal of Mental Health Systems, 5, 1-11. DOI https://doi.org/10.1186/1752-4458-5-6.

Kigozi, F., Ssebunnya, J., Kizza, D., et al (2010) An overview of Uganda's mental health care system: results from an assessment using the World Health Organization's Assessment Instrument for Mental Health Systems (WHO-AIMS). International Journal of Mental Health Systems, 4, 1-9. DOI https://doi.org/10.1186/1752 4458-4-1.

Kiima, D. \& Jenkins, R. (2010) Mental health policy in Kenyaan integrated approach to scaling up equitable care for poor populations. International Journal of Mental Health Systems, 4, 19. 1DOI https://doi.org/0.1186/1752-4458-4-19.

Marais, D. L. \& Peterson, I. (2015) Health system governance to support integrated mental health care in South Africa: challenges and opportunities. International Journal of Mental Health Systems, 9, 14. DOI https://doi.org/10.1186/s13033-015-0004-z.

Monteiro, N. M., Ndiaye, Y., Blanas, D., et al (2014) Policy perspectives and attitudes towards mental health treatment in rural Senegal. International Journal of Mental Health Systems, 8, 1-9. DOI https://doi.org/10.1186/1752-4458-8-9.

Muga, A. F. \& Jenkins, R. (2010) Health care models guiding mental health policy in Kenya 1965-1997. International Journal of Mental Health Systems, 4, 9. DOI https://doi.org/10.1186/1752-4458-4-9.

Omar, M. A., Green, A. T., Bird, P. K., et al (2010) Mental health policy process: a comparative study of Ghana, South Africa, Uganda and Zambia. International Journal of Mental Health Systems, 4, 24. DOI https://doi.org/10.1186/1752-4458-4-24.

Petersen, I., Ssebunnya, J., Bhana, A., et al (2011) Lessons from case studies of integrating mental health into primary health care in South Africa and Uganda. International Journal of Mental Health Systems, 5, 8. DOI https://doi.org/10.1186/1752-4458-5-8.

Raja, S., Wood, S. K., de Menil, V., et al (2010) Mapping mental health finances in Ghana, Uganda, Sri Lanka, India and Lao PDR. International Journal of Mental Health Systems, 4, 11. DOI https:// doi.org/10.1186/1752-4458-4-11. 